Erzsébet Illés, Márta Szekeres, Ildikó Y. Tóth, Ákos Szabó, Béla Iván, Rodica Turcu, Ladislau Vékás, István Zupkó, György Jaics, Etelka Tombácz

Multifunctional PEG-carboxylate copolymer coated superparamagnetic iron oxide nanoparticles for biomedical application

JOURNAL OF MAGNETISM AND MAGNETIC MATERIALS 451: pp. 710-720. (2018)

\title{
Multifunctional PEG-carboxylate copolymer coated superparamagnetic iron oxide nanoparticles for biomedical application
}

Erzsébet Illés $^{1^{*}}$, Márta Szekeres ${ }^{1}$, Ildikó Y. Tóth ${ }^{1}$, Ákos Szabó ${ }^{2}$ Béla Iván ${ }^{2}$, Rodica Turcu ${ }^{3}$, Ladislau Vékás ${ }^{4}$, István Zupkó ${ }^{5}$, György Jaics ${ }^{1}$ Etelka Tombácz ${ }^{1 *}$

${ }^{1}$ Department of Physical Chemistry and Materials Science, University of Szeged, Aradi Vt. 1, H-6720 Szeged, Hungary

${ }^{2}$ Polymer Chemistry Research Group, Institute of Materials and Environmental Chemistry, Research Centre for Natural Sciences, Hungarian Academy of Sciences, P.O. Box 286, H1519 Budapest, Hungary

${ }^{3}$ National Institute R\&D for Isotopic and Molecular Technologies, 67-103 Donat Str., RO400293 Cluj-Napoca, Romania

${ }^{4}$ Center for Fundamental and Advanced Technical Research, Mihai Viteazul Str. 24300223 Timisoara, Romania

${ }^{5}$ Department of Pharmacodynamics and Biopharmacy, University of Szeged, Eötvös u. 1, H6720 Szeged, Hungary

*corresponding author

Erzsébet Illés, illese@ chem.u-szeged.hu

\section{Highlights}

- Multicore magnetite nanoparticles (MNPs) were superparamagnetic.

- PEG-carboxylate polyelectrolytes coat spontaneously MNPs and stabilize them electrosterically.

- Biofunction can be attached to MNPs via carboxylated coating layer.

- Multifunctional shell prevents MNPs' internalization into cells.

- Superparamagnetic property is sustained after MNP coating. 


\begin{abstract}
Biocompatible magnetite nanoparticles (MNPs) were prepared by post-coating the magnetic nanocores with a synthetic polymer designed specifically to shield the particles from nonspecific interaction with cells. Poly(ethylene glycol) methyl ether methacrylate (PEGMA) macromonomers and acrylic acid (AA) small molecular monomers were chemically coupled by quasi-living atom transfer radical polymerization (ATRP) to a comb-like copolymer, $\mathrm{P}$ (PEGMA-co-AA) designated here as P(PEGMA-AA). The polymer contains pendant carboxylate moieties near the backbone and PEG side chains. It is able to bind spontaneously to MNPs; stabilize the particles electrostatically via the carboxylate moieties and sterically via the PEG moieties; provide high protein repellency via the structured PEG layer; and anchor bioactive proteins via peptide bond formation with the free carboxylate groups. The presence of the P(PEGMA-AA) coating was verified in XPS experiments. The electrosteric (i.e., combined electrostatic and steric) stabilization is efficient down to $\mathrm{pH} 4$ (at $10 \mathrm{mM}$ ionic strength). Static magnetization and AC susceptibility measurements showed that the P(PEGMA-AA)@MNPs are superparamagnetic with a saturation magnetization value of 55 $\mathrm{emu} / \mathrm{g}$ and that both single core nanoparticles and multicore structures are present in the samples. The multicore components make our product well suited for magnetic hyperthermia applications (SAR values up to $17.44 \mathrm{~W} / \mathrm{g}$ ). In vitro biocompatibility, cell internalization, and magnetic hyperthermia studies demonstrate the excellent theranostic potential of our product.
\end{abstract}

\title{
Graphical abstract
}

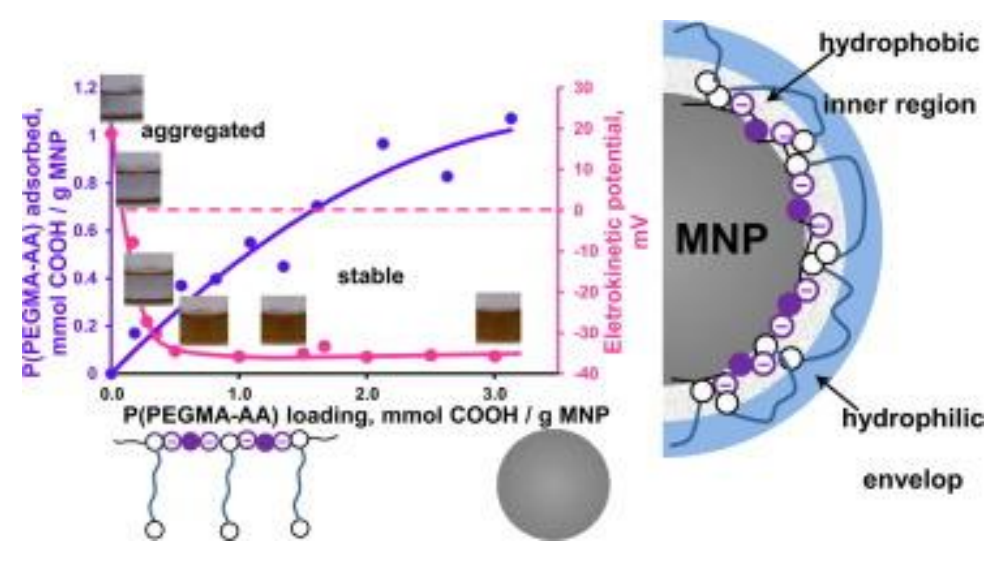

Keywords

Core-shell nanoparticles, Superparamagnetic iron oxide nanoparticles (SPIONs), PEGylation, Colloidal stability, Cell internalization, Theranostics. 


\section{Introduction}

The theranostic potential of superparamagnetic iron oxide nanoparticles (SPIONs) with suitable core size, biocompatible coating and surface functionalities have long been acknowledged in specific applications such as MRI contrasting, hyperthermia and targeted drug delivery [1-3]. Their biomedical applicability depends also on the chemical and colloidal stability in biological media [4] and on the interaction with proteins to either enhance or reduce their cellular uptake according to biomedical demand.

A large variety of SPION surface coatings using synthetic or natural polymers have been developed to improve biocompatibility and colloidal stability in biological environment $[5,6]$. The polymer shells can also offer grafting sites for covalent immobilization of biomolecules such as aptamers or antibodies, or functional groups for reversible immobilization of bio-entities (e.g. DNA). Perhaps the most successful core-shell products are carboxylgroup functionalized SPIONs, since they are not only easy to functionalize in a huge variety of reactions of the carboxyl groups, but also provide high stability to SPIONs in a biological milieu by decreasing the isoelectric point $\left(\mathrm{pH}_{\mathrm{iep}}\right)$ of iron oxide nanoparticles [7-11]. However, protein adsorption occurs on the surface of carboxylated SPIONs and the formation of hard/soft protein coronas $[12,13]$ can give rise to cellular recognition of the nanoparticles by phagocytes or inflammatory cells (opsonization), which reduce significantly the efficiency of active targeting and may cause problems in their application in vivo.

PEGylation, i.e. coating the surface of nanoparticles via covalent or non-covalent attachment of polyethylene glycol (PEG) [14] also called polyethylene oxide (PEO is one of the most favored ways to fabricate nanoparticles for biomedical application $[15,16]$ due to the high hydrophilicity of PEG chains [17].

Polymers in general are chemically or physico-chemically attached to nanoparticle surfaces via grafting or adsorption, respectively. Grafting of PEG on SPIONs' surface is efficient and straightforward [5], but it has a serious drawback that the organic chemical reactions require harsh conditions (high temperature, organic solvents) detrimental for the majority of bioactive groups attached to the chains in advance, for example, in PEG-bioactive molecule conjugates (prodrugs).

When mild reaction conditions are required, physico-chemical attachment methods are better suited for nanoparticle coating than chemical grafting [4]. Various compounds, among them functionalized PEG-polymers, are widely used for in situ coating [18, 19]. During this so called one-pot method, the nanoparticles are synthesized in the presence of the coating 
agent applied in high excess for successful control of the size and shape of the emerging coreshell nanoparticles. However, non-uniform products of undefined composition can also be formed in this method at high concentration. Alternatively, post-coating can be used to coat the purified nanoparticles prepared separately. Although this method is more time-consuming, the sample composition is well-defined and there are practically no synthesis residues. Instead of simple polymers, N'Guyen and coworkers [20] suggested to use polymers with three different functionalities (tri-functional molecules). One functional group in their study enabled strong binding of the polymer to the nanoparticle, another one (a hydrophilic sequence of PEG chains) ensured protection against aggregation and protein fouling and a third free moiety allowed coupling of a biologically active molecule for medical effect. Versatile tri-functional molecules of this kind can be synthesized for specifically defined applications.

Our aim was to synthesize a novel multi-functional copolymer and to prepare coreshell magnetite nanoparticles with its help (designated as MNPs throughout the present study) by the post-coating synthesis method in order to (i) improve colloidal stability in the biological media, (ii) prevent protein fouling and cell internalization while providing free sites for anchoring bioactive agents and, (iii) sustain the original high magnetic profile of the superparamagnetic nanoparticles suitable for theranostics.

The copolymer was comprised of free carboxylate (acrylic acid, AA) and PEG segments arranged in a comb-like structure. This coating would still ensure the highest possible colloidal stability in biorelevant media via the electrosteric (i.e., combined electrostatic and steric) mechanism. The random comb-like copolymer P(PEGMA-co-AA), designated here as $\mathrm{P}(\mathrm{PEGMA}-\mathrm{AA})$, was prepared by quasi-living atom transfer radical polymerization (ATRP) [21]. The carboxylates of the AA moieties can serve triple aims. A part of them could bind multiply to the surface of the magnetite such as PAA (polyacrylic acid) [7] or PAM (poly(acrylic-co-maleic acid) [8], the remaining groups would be available for electrostatic stabilization and also for functionalization with bioactive molecules or drugs. The hydrophilic segments (PEG chains) could protect the particles against protein fouling and enhance their stability by steric effect.

Here we report on the synthesis, morphology, colloidal stability, and magnetic properties of naked and core-shell MNPs and in vitro interaction of core-shell MNPs with human cells. TEM, XPS, dynamic light scattering (DLS) and electrophoretic mobility (zeta potential) experiments were carried out to detect the presence of P(PEGMA-AA) shell on MNPs and its effect on colloidal behavior in biologically relevant media. The magnetic 
response was tested in static and dynamic experiments. The theranostic potential of the P(PEGMA-AA) coated MNPs was investigated in magnetic hyperthermia, cell proliferation (MTT), and cell internalization experiments in vitro.

\section{Materials and methods}

\subsection{Polymer and nanoparticle synthesis}

Acrylic acid (AA), L-ascorbic acid, ethyl 2-bromoisobutyrate, 1,1,4,7,10,10hexamethyltriethylenetetraamine (HMTETA) and trifluoroacetic acid were used as received. The poly(ethylene glycol) methyl ether methacrylate macromonomer (PEGMA300, $M_{\mathrm{n}}=300$ $\mathrm{g} / \mathrm{mol}$ ) was used after purification by passing through a column filled with neutral $\mathrm{Al}_{2} \mathrm{O}_{3}$. Tert-butyl acrylate $(t \mathrm{BuA})$ was purified via vacuum distillation. Toluene was distilled over sodium/benzofenone and dichloromethane over calcium hydride. $\mathrm{Cu}(\mathrm{I})$-chloride was stirred with acetic acid overnight, filtered and washed with absolute ethanol and diethyl ether before use.

The P(PEGMA-AA) copolymer was synthesized via quasiliving atom transfer radical polymerization (ATRP) performed at $40{ }^{\circ} \mathrm{C}$ using ethyl 2-bromoisobutyrate as initiator, HMTETA as complexing agent and $\mathrm{Cu}(\mathrm{I})$-chloride as catalyst in 1:1:1 initiator:HMTETA:catalyst molar ratio. L-Ascorbic acid was added to the synthesis mixture to prevent irreversible oxidation of the $\mathrm{Cu}(\mathrm{I})$ catalyst. The total monomer mass to toluene solvent volume ratio was $1 \mathrm{~g}: 2 \mathrm{ml}$. The starting random copolymer P(PEGMA-co- $t \mathrm{BuA})$ was prepared using $50 \mathrm{w} \%(0.167 \mathrm{~mol} / 100 \mathrm{~g}$ monomer mixture) of PEGMA300 and $50 \mathrm{w} \%(0.39$ mol/100 g monomer mixture) of $t \mathrm{Bu}-\mathrm{A}$ monomers. The ATRP reaction mixtures were purified by passing through neutral $\mathrm{Al}_{2} \mathrm{O}_{3}$ column. The P(PEGMA-co- $\left.t \mathrm{BuA}\right)$ copolymer was transformed to the acrylic acid form P(PEGMA-AA) via acidic hydrolysis performed by adding trifluoroacetic acid (10-fold molar excess related to $t \mathrm{BuA})$ to the solution of the polymer in dichloromethane, followed by stirring overnight and precipitation in hexane. The structure of the obtained comb-like copolymer product is shown in Fig. 1.The number average molar mass was determined by gel permeation chromatography in tetrahydrofuran.

Throughout the paper, the molar amounts of carboxyl groups were used to express the concentration of carboxylated compounds designated as - $\mathrm{COO}$ meaning both the protonated and deprotonated states.

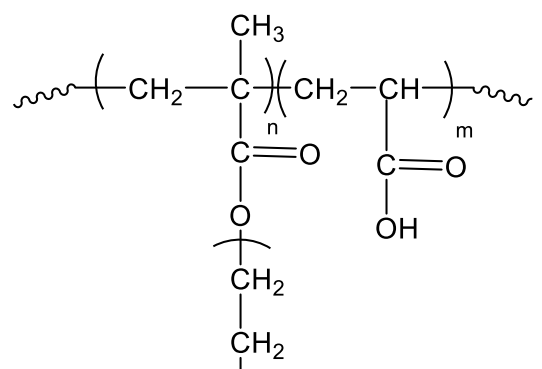


Fig. 1. The structure of the synthesized random comb-like copolymer P(PEGMA-AA) with carbon-carbon backnone, PEG side chains and free acrylic acid moieties. The number of PEGMA and AA monomers and the EO units in PEGMA are $m=31, n=13$ and $z=4.5$, respectively.

Magnetite nanoparticles (MNPs) were prepared by a co-precipitation method detailed for example in [10] and in some of our previous and recent papers [7, 8, 22]. Concentrated $\mathrm{FeCl}_{2} \cdot 4 \mathrm{H}_{2} \mathrm{O}$ and $\mathrm{FeCl}_{3} \cdot 6 \mathrm{H}_{2} \mathrm{O}$ (Molar, Hungary) solutions were mixed at a $1: 2$ ratio of $\mathrm{Fe}(\mathrm{II})$ to $\mathrm{Fe}(\mathrm{III})$ and precipitated by $\mathrm{NaOH}$ (Molar, Hungary) solution. The MNPs were washed with ultrapure water and acidified by $\mathrm{HCl}$ (Molar, Hungary) to obtain a stable aqueous dispersion. The MNPs were further purified by dialysis against $1 \mathrm{mM} \mathrm{HCl}$ solution, magnetically decanted and stored at $4{ }^{\circ} \mathrm{C}$ in dark. The crystalline structure of the synthesized iron oxide was identified as magnetite $\left(\mathrm{Fe}_{3} \mathrm{O}_{4}\right)$ based on the JCPDS database [23]. X-ray diffraction (XRD) analysis was performed by using a Philips PW 1830/PW 1820 X-ray diffractometer operating in the reflection mode with CuK $\alpha$ radiation. The average diameter of the MNPs was $\sim 10.2 \mathrm{~nm}$ determined from the broadening of the most intensive peak of the XRD pattern by using the Scherrer equation [22]. The primary size of the synthesized MNPs was $\sim 10 \mathrm{~nm}$ as determined by using a FEI Tecnai G2 transmission electron microscope.

The P(PEGMA-AA)@MNPs were prepared by mixing P(PEGMA-AA) solutions and MNP stock dispersions in calculated amounts between 0 and $2.2 \mathrm{mmol}-\mathrm{COO} / \mathrm{g} \mathrm{MNP}$ in order to achieve optimal loading values. The latter range of loadings is selected on the basis of our earlier studies [4, 7-9]. The desired $\mathrm{pH}$ and ionic strength values were adjusted after the dispersion preparation by using $\mathrm{HCl}, \mathrm{NaOH}$ and $\mathrm{NaCl}$ solutions and readjusted before each subsequent experiment. For the application in in vitro experiments, a stock dispersion was prepared at MNP concentration of $10 \mathrm{mg} / \mathrm{mL}, \mathrm{P}(\mathrm{PEGMA}-\mathrm{AA})$ loading of $1 \mathrm{mmol}-\mathrm{COO} / \mathrm{g}$ $\mathrm{MNP}$ and $\mathrm{pH} \sim 6.5$. Any excess polymer was removed by acidifying the dispersion to $\mathrm{pH}=2$, 
collecting the sediment by using a permanent magnet and re-dispersing it in a fresh medium at $\mathrm{pH} \sim 6.5$.

\subsection{Transmission Electron Microscopy (HR-TEM)}

Transmission Electron Micrographs of naked MNPs and P(PEGMA-AA)@MNPs were taken in a FEI Tecnai G2 microscope at an accelerating voltage of $80 \mathrm{kV}$. Particles were deposited onto a carbon coated copper grid from highly diluted suspensions by traditional wicking procedure. The average size distribution was determined by evaluating 200 particles using the JMicrovision 1.27 software.

\subsection{X-ray Photoelectron Spectroscopy (XPS)}

The chemical composition (atomic concentrations) on the surface, as well as the chemical state of the atoms of the pure copolymer P(PEGMA-AA) and the coated nanoparticles P(PEGMA-AA)@MNP were determined by X-ray Photoelectron Spectroscopy (XPS). The spectra were recorded using a spectrometer SPECS equipped with a dual-anode X-ray source Al/Mg, a PHOIBOS 150 2D CCD hemispherical energy analyzer and a multichanneltron detector with vacuum maintained at $1 \times 10^{-9}$ torr. The $\mathrm{Al}_{\mathrm{K} \alpha} \mathrm{X}$-ray source $(1486.6$ eV) operated at $200 \mathrm{~W}$ was used for XPS investigations. The XPS survey spectra were recorded at $30 \mathrm{eV}$ pass energy and $0.5 \mathrm{eV} / \mathrm{step}$. The high-resolution spectra for individual elements were recorded by accumulating 10 scans at $30 \mathrm{eV}$ pass energy and $0.1 \mathrm{eV} / \mathrm{step}$. The powder suspensions were dried on an indium foil to allow the XPS measurements. A cleaning of the samples surface was performed by argon ion bombardment (300 V). Data analysis and curve fitting was performed using CasaXPS software with a Gaussian-Lorentzian product function and a non-linear Shirley background subtraction.

\subsection{Electrophoresis measurements}

The zeta potential of the uncoated magnetite and the adsorbate-loaded nanomagnets P(PEGMA-AA)@MNP were determined in a Nano ZS (Malvern) dynamic light scattering (DLS) apparatus with a $4 \mathrm{~mW} \mathrm{He}-\mathrm{Ne}$ laser source $(\lambda=633 \mathrm{~nm})$. The electrophoretic mobilities were recorded at $25 \pm 0.1{ }^{\circ} \mathrm{C}$ using disposable zeta cells (DTS 1061) and the Smoluchowski equation was applied to convert them to zeta potentials. The accuracy of the measurements is $\pm 5 \mathrm{mV}$ and the zeta-standard of Malvern $(-55 \pm 5 \mathrm{mV})$ was used for calibration. The dispersions were diluted to give an optimal intensity of $\sim 10^{5}$ counts per 
second. Prior to the measurements, the samples were homogenized in an ultrasonic bath for $10 \mathrm{~s}$, after which 2 min relaxation was allowed. The influence of polymer loading (0-2 mmol $-\mathrm{COO} / \mathrm{g} \mathrm{MNP}$ ) on the zeta potential of MNPs was determined at $\mathrm{pH} \sim 6.5$ and $I=10 \mathrm{mM}$ $(\mathrm{NaCl})$. The $\mathrm{pH}$-dependent surface charging properties of the naked and coated nanomagnets were studied from $\mathrm{pH} 3$ to $\sim 10$ at $I=10 \mathrm{mM}$.

\subsection{Mean particle size determination via dynamic light scattering (DLS)}

The average particle size of bare magnetite and coated core-shell nanoparticles was determined at $25 \pm 0.1^{\circ} \mathrm{C}$ using a Nano ZS (Malvern) apparatus operating in backscattering mode at an angle of $173^{\circ}$. The solution conditions were the same as in the electrophoresis measurements: the added amounts of P(PEGMA-AA) varied between 0 and $2 \mathrm{mmol} / \mathrm{g}$ MNP, the $\mathrm{pH}$ range between $\sim 3$ and $\sim 10$ and the ionic strength $(I)$ was $10 \mathrm{mM}(\mathrm{NaCl})$. The aggregation state of the nanoparticles in the aqueous dispersions was characterized by the intensity average hydrodynamic diameter ( $Z$ Average) values. We used the second- or thirdorder cumulant fit of the autocorrelation functions, depending on the degree of polydispersity. The variation of Z-Ave values was less than $5 \%$ for primary particles and the error definition becomes irrelevant for large polydisperse aggregates.

\subsection{Magnetic characterization}

For magnetic characterization, the naked MNP dispersions were prepared at $\mathrm{pH} \sim 4$ and $33 \mathrm{~g} / \mathrm{L}$ concentration and the P(PEGMA-AA)@MNP dispersions at $\mathrm{pH} \sim 6.5$ and $10 \mathrm{~g} / \mathrm{L}$ concentration and the ionic strength was set to $I=10 \mathrm{~mm}$. The P(PEGMA-AA) loading was 1 $\mathrm{mmol}-\mathrm{COO} / \mathrm{g} \mathrm{MNP}$.

The magnetization curves of the uncoated MNPs and P(PEGMA-AA)@MNPs were obtained by a vibrating sample magnetometer VSM880 (DMS/ADE Technologies USA) at the RCESCFUP Timisoara. The measurements were performed at room temperature on stable aqueous MNP sols at $\sim 10 \%$ by weight and the maximum of the applied field was $\sim 840 \mathrm{kA} / \mathrm{m}$. The value of specific magnetization was related to the actual amount of MNP.

The magnetic susceptibility of bare and P(PEGMA-AA) coated MNPs was measured by a DynoMag AC susceptometer (Acreo, Sweden). Both the real and the imaginary part of the magnetic susceptibility were determined in the frequency range of $10-300 \mathrm{kHz}$ in $200 \mu \mathrm{l}$ samples. The measured susceptibility values were then analysed using a built-in toolbox for multi- and single core particles. Multi-core (extended) model was applied to fit the experimental data by assuming a lognormal particle size distribution. 
The magnetic hyperthermic efficiency of P(PEGMA-AA)@MNPs was tested in two separate experiments by using a magneTherm TM (nanoTherics Ltd., Keele, Staffordshire, UK) and a DM100 (nB nanoscale Biomagnetics, Zaragoza, Spain) instrument. The volumes of MNP dispersions were $4 \mathrm{~mL}$ (with dispersion concentration of $15 \mathrm{~g} / \mathrm{L}$ ) and $1 \mathrm{~mL}$ (with dispersion concentration of $5 \mathrm{~g} / \mathrm{L}$ ) in the magneTherm and the DM100 experiments, respectively. To enhance reproducibility, the samples were added by weight directly into the sample holders. The measurements were performed at resonant frequencies of $110.7 \mathrm{kHz}$ with magnetic field values of $\mathrm{B}=24.6,20.58,14.4,9.14$ and $6.17 \mathrm{mT}$ by using a 17 turn coil / 198 $\mathrm{nF}$ capacitor and at $329 \mathrm{kHz}$ with $\mathrm{B}=16.49,13.74$ and $6.87 \mathrm{mT}$ by using a 17 turn coil / 22 $\mathrm{nF}$ capacitor. The measurement time was 5 minutes. The specific absorption rate (SAR, W/g magnetite) values for the different field strength values were calculated according to $\mathrm{SAR}=\left(\mathrm{C}_{\mathrm{p}, \mathrm{s}} \mathrm{m}_{\text {water }} / \mathrm{m}_{\mathrm{P}(\mathrm{PEGMA}-\mathrm{AA}) @ \mathrm{MNP})}\right)^{*}(\Delta \mathrm{T} / \Delta \mathrm{t})$, where $\mathrm{C}_{\mathrm{p}, \mathrm{s}}$ is the specific heat capacity of the medium (water), $\mathrm{m}_{\text {water }}$ and $\mathrm{m}_{\mathrm{P}(\mathrm{PEGMA}-\mathrm{AA}) @ \mathrm{MNP}}$ are the masses of the medium and the nanoparticles, and $\Delta \mathrm{T} / \Delta \mathrm{t}$ is the temperature rate at $\mathrm{t}=0$.

\section{7. in vitro interaction of $\mathrm{P}(\mathrm{PEGMA-AA}) @ M N P$ s with cells}

The anti-proliferative capacity of the P(PEGMA-AA)@MNPs was measured in vitro in MCF7 and T47D human breast cancer cell cultures by using the MTT ([3-(4,5dimethylthiazol-2-yl)-2,5-diphenyltetrazolium bromide]) cell viability assay [24, 25]. The cells were purchased from ECACC (European Collection of Cell Cultures, Salisbury, UK), and cultivated in minimal essential medium supplemented with $10 \%$ foetal bovine serum, $1 \%$ non-essential amino acids and an antibiotic antimytotic mixture. All media and supplements were obtained from Life Technologies (Paisley, UK). The cells were grown in a humidified atmosphere of $5 \% \mathrm{CO}_{2}$ at $37{ }^{\circ} \mathrm{C}$. Briefly, a limited number of human cancer cells (5000/well) were seeded onto a 96-well microplate and attached to the bottom of the well overnight. On the second day of the procedure, the original medium was removed, and $200 \mu \mathrm{L}$ of a new medium, containing the P(PEGMA-AA)-covered magnetite in concentrations of 10 or 30 $\mathrm{mg} / \mathrm{L}$, was added. After incubation for $72 \mathrm{~h}$, the living cells were assayed by the addition of $20 \mu \mathrm{L}$ of $5 \mathrm{mg} / \mathrm{mL}$ MTT solution. MTT was converted by intact mitochondrial reductase and precipitated as blue crystals during a 4-hour contact period. The medium was then removed, and the precipitated crystals were dissolved in $100 \mu \mathrm{L}$ of dimethyl sulphoxide during a 60min period of shaking. Finally, the reduced MTT was assayed at $545 \mathrm{~nm}$, using a microplate reader. All experiments were conducted in duplicate with five parallel wells, and wells with 
untreated cells were utilized as controls. Cisplatin was used as a reference compound. The calculations of the results were outperformed using GraphPad Prism 2.01 (GraphPad Software, San Diego, CA, USA).

The distribution of P(PEGMA-AA)@MNPs in the human cervix adenocarcinoma cell (HeLa, ECACC, Salisbury, UK) culture was tested via Prussian blue staining method analogously to our previous work [4]. The cells were cultivated in minimal essential medium supplemented with $10 \%$ fetal bovine serum, $1 \%$ non-essential amino acids and an antibioticantimycotic mixture (PAA Laboratories $\mathrm{GmbH}$, Pasching, Austria). Near-confluent cancer cells were seeded onto a 96-well micro-plate at the density of 5000 cells/well. A $200 \mu \mathrm{L}$ aliquot of MEM containing the P(PEGMA-AA)@MNPs at $10 \mathrm{mg} / \mathrm{L}$ concentration was added to the cells cultured overnight. After $48 \mathrm{~h}$ incubation with MNPs at $37{ }^{\circ} \mathrm{C}$ in humidified air containing $5 \% \mathrm{CO}_{2}$, Prussian blue staining was used to visualize the presence of ferric ions. The medium was removed and a 1:1 mixture of $2 \%$ potassium ferrocyanide and $2 \%$ hydrochloric acid was added for $10 \mathrm{~min}$. Then the wells were washed with phosphatebuffered saline and the cells were photographed by means of a Nikon Eclipse microscope with a QCapture CCD camera.

\section{Results and discussions}

\subsection{Size and morphology of the naked and core-shell MNPs}

Transmission electron microscopy studies reveal that the main particle diameter of the MNPs is around $10 \mathrm{~nm}$ both before and after surface modification with the P(PEGMA-AA) copolymer (Fig. 2). The nanomagnets synthesized in a co-precipitation method are nearly
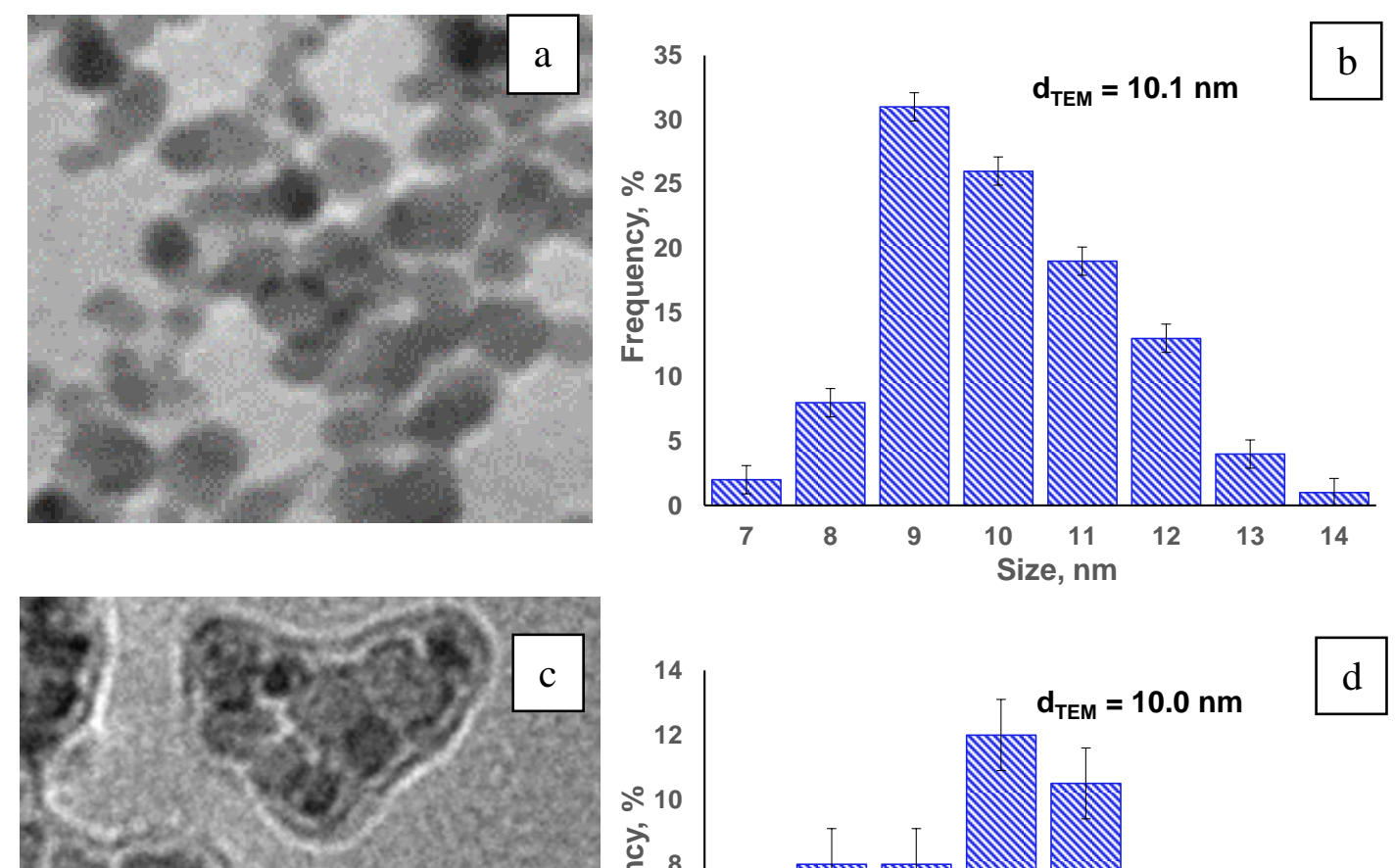
Fig. 2. TEM images and particle size distributions of naked magnetite nanoparticles $(a, b)$ and P(PEGMA-AA) coated nanomagnets $(\mathrm{c}, \mathrm{d})$ deposited on carbon coated copper grid.

spherical and slightly polydisperse and comprise a mixture of single and multi-core particles [26,27]. According to the size distribution analysis, the average primary particle diameter values are $10.1 \pm 1.1 \mathrm{~nm}$ for the bare and $10.0 \pm 1.4 \mathrm{~nm}$ for the coated MNPs. It is in good agreement with former TEM [4] and X-ray diffraction [22] results. The subtle difference in the size distribution functions (Figs. $2 b$ and $2 d$ ) cannot lead to significantly different mean particle diameters for the naked and coated MNPs because of the relatively high polydispersity. The TEM pictures indicate the presence of polymer coating in the P(PEGMAAA)@MNP samples. For TEM imaging of core-shell MNPs, we applied the method worked out by Ahmadi et al [28], in which a low voltage of $80 \mathrm{kV}$ is used to be able to detect the organic coating. The polymer shell around the well separated particles can be estimated as 2$2.3 \mathrm{~nm}$ thick, similarly to shell thickness around MNPs found by Ahmadi [28] and Kumar [29]. The thickness of the P(PEGMA-AA) layer in the confined space between particles appears to be significantly smaller: $1.5-1.7 \mathrm{~nm}$. Occasional particle crowding can be seen in the pictures, which can be caused by the high compression forces during the drying step of TEM sample preparation [30,31]. The increased pressure can lead to conformational changes of the polymer chains and to subsequent shrinking of the coating layer. It is clearly revealed in Fig. 2c that the MNP cores do not contact each other directly because of the presence of polymer shell between them. TEM pictures of surfactant-coated MNPs [32,33] also indicated that the coatings on nanomagnets can act as spacer between the particles. 


\subsection{Surface chemistry of the core-shell MNPs}

XPS studies of pure P(PEGMA-AA) and P(PEGMA-AA)@MNPs confirmed the presence of the coating layer on MNPs surface altering its surface chemistry. Detailed FTIRATR analysis of the molecular binding modes of P(PEGMA-AA) to magnetite nanoparticles will be given in a subsequent publication.

The Fe 2p core-level high resolution XPS spectrum of P(PEGMA-AA)@MNP and the $\mathrm{C} 1 \mathrm{~s}$ and O1s spectra of P(PEGMA-AA) solution and P(PEGMA-AA)@MNP core-shell nanoparticles are shown in Fig. 3. The fitting parameters for peak position, peak breadth and atomic concentration calculated from peak areas are given in Table 1.

The Fe 2p spectrum of P(PEGMA-AA)-coated MNPs (Fig. 3a) contains the doublet of $\mathrm{Fe} 2 \mathrm{p} 3 / 2$ and $\mathrm{Fe} 2 \mathrm{p} 1 / 2$ (corresponding to $\mathrm{Fe}^{3+}$ and $\mathrm{Fe}^{2+}$ ions) and their satellites [34-37 ]. The best fits of C 1s spectra (Fig. 3b, c) were obtained with the components of 284.77, 286.31 and $288.51 \mathrm{eV}$ assigned to carbon atoms in $\mathrm{C}-\mathrm{C} / \mathrm{C}-\mathrm{H}, \mathrm{C}-\mathrm{O}-\mathrm{C}$ (oxide 1: alcohols and ethers) [38] and $\mathrm{O}-\mathrm{C}=\mathrm{O}$ (oxide 3: carboxyls and esters) [38], respectively. The peaks in $\mathrm{O}$ 1s spectra (Fig. 3d,e) can be assigned to In-O (of indium support), $\mathrm{Fe}-\mathrm{O}(530.41 \mathrm{eV}$ ), $\mathrm{C}-\mathrm{O}-\mathrm{C}(531.9 \mathrm{eV})$ and $\mathrm{O}-\mathrm{C}=\mathrm{O}(533.04 \mathrm{eV})$ bonds and chemisorbed water molecules $(535.36 \mathrm{eV})$. All the binding energy values of $\mathrm{C} 1 \mathrm{~s}$ and $\mathrm{O} 1 \mathrm{~s}$ electrons of P(PEGMA-AA) shifted upon its adsorption to MNPs. The small decrease in the chemical shift of $\mathrm{C} 1 \mathrm{~s}$ electrons in $\mathrm{C}-\mathrm{C} / \mathrm{C}-\mathrm{H}$ bonds can be due to the decreased contact of the methyl $\left(-\mathrm{CH}_{3}\right)$ groups of adsorbed P(PEGMA-AA) with the aqueous environment. The chemical shift of $\mathrm{O}$ 1s electrons in $\mathrm{C}-\mathrm{O}$ (ether oxygens) of $\mathrm{P}(\mathrm{PEGMA}-\mathrm{AA})$ also decreased in the course of
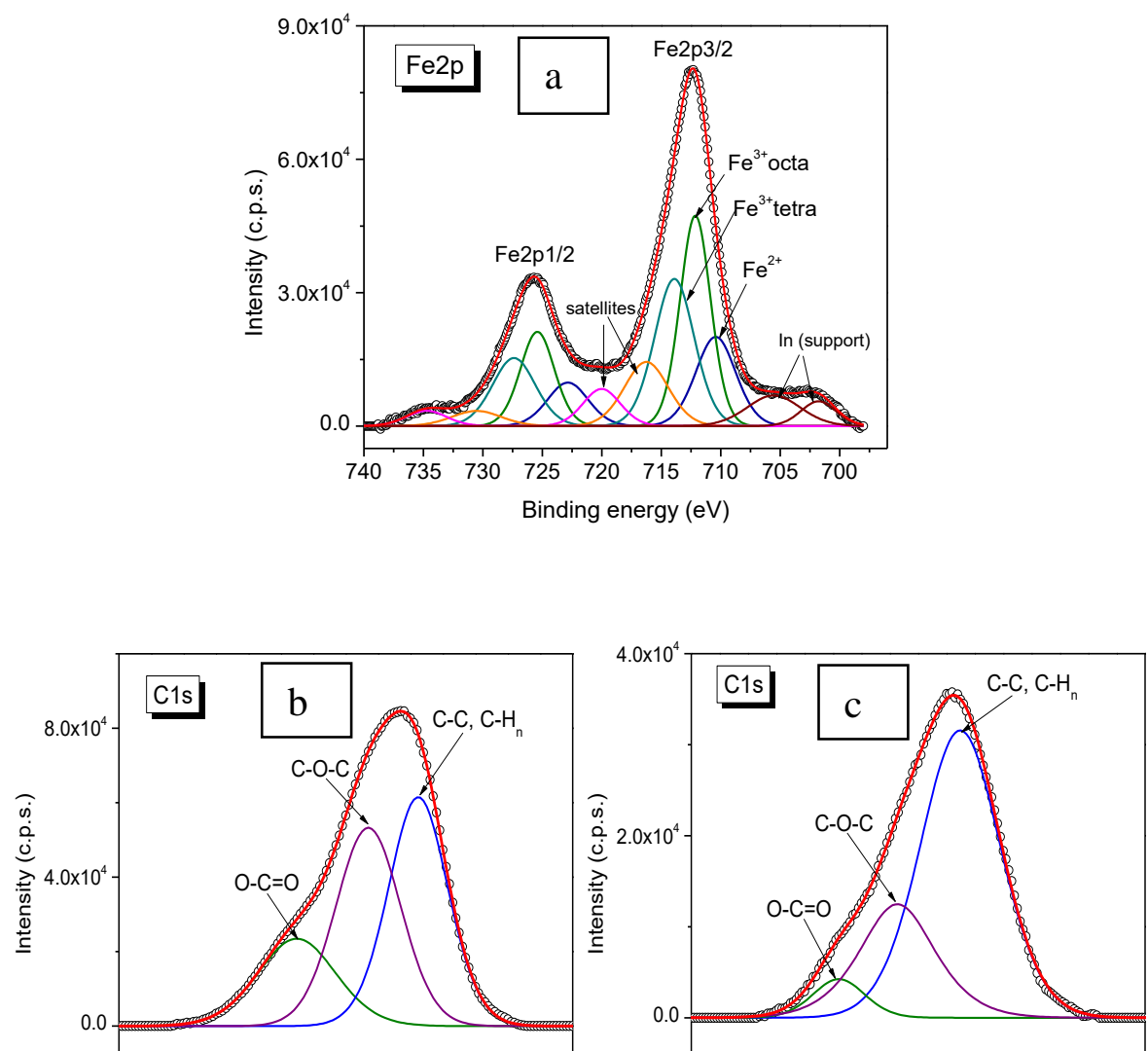

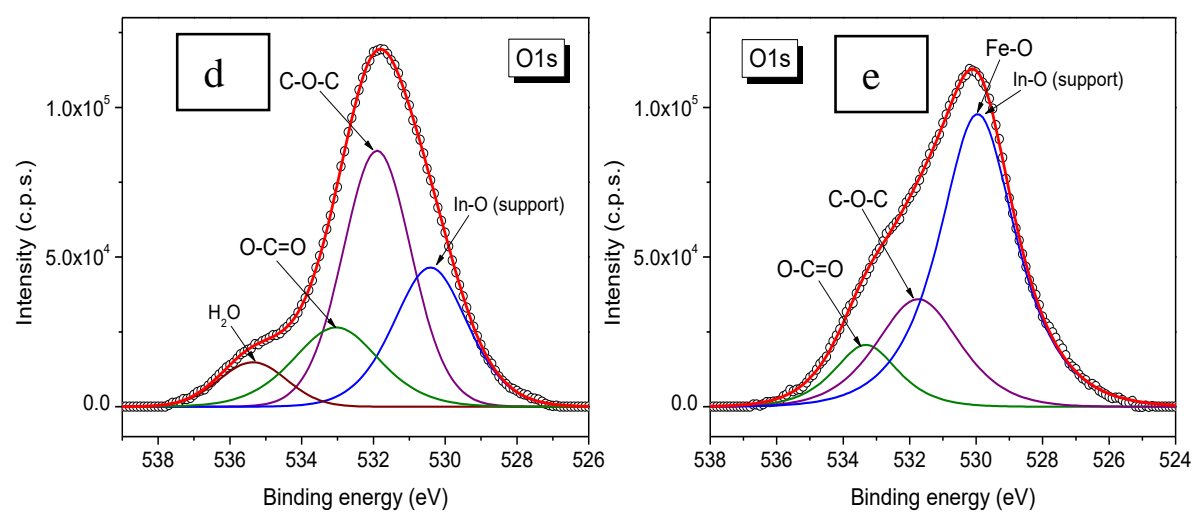

Fig. 3. High resolution XPS spectra of Fe 2p core level from P(PEGMA-AA)@MNP sample (a), C1s, O1s core levels from pure P(PEGMA-AA) copolymer (b, d) and P(PEGMAAA)@MNP (c, e) samples.

adsorption. The latter could be induced by the decrease in the electronegativity of the environment, for example, by the proximity of low electronegativity Fe atoms (as compared to that of $\mathrm{O}, \mathrm{C}$ and $\mathrm{H}$ of the polymer). A small increase in the chemical shift of the $\mathrm{C} 1 \mathrm{~s}$ of oxides 1 and 3 and the ester (or carboxyl) $\mathrm{O} 1 \mathrm{~s}$ peaks indicates that these groups can contribute to the adsorption directly as opposed with the indirect contribution of $\mathrm{CH}_{3}$ and ether oxygens.

Table 1. The fitting parameters (peak positions, full width at half maximum (FWHM) and atomic concentrations calculated from peak areas) of $\mathrm{C} 1 \mathrm{~s}$, O1s and Fe 2p spectra (Fig. 3) for P(PEGMA-AA) copolymer (before adsorption) and P(PEGMA-AA)@MNP (after adsorption).

\begin{tabular}{l|lll|lll}
\hline Peak name & Position & FWHM & Atomic & Position & FWHM & Atomic \\
\hline
\end{tabular}




\begin{tabular}{|c|c|c|c|c|c|c|}
\hline & $(\mathrm{eV})$ & $(\mathrm{eV})$ & conc $(\%)$ & $(\mathrm{eV})$ & $(\mathrm{eV})$ & conc $(\%)$ \\
\hline & \multicolumn{3}{|c|}{ P(PEGMA-AA) } & \multicolumn{3}{|c|}{ P(PEGMA-AA)@MNP } \\
\hline $\mathrm{C} 1 \mathrm{~s}, \mathrm{C}-\mathrm{C},-\mathrm{C}-\mathrm{H}$ & 284.77 & 2.158 & 29.468 & 284.52 & 3.297 & 27.624 \\
\hline $\mathrm{C} 1 \mathrm{~s}, \mathrm{C}-\mathrm{O}-\mathrm{C}$ & 286.31 & 2.355 & 27.622 & 286.73 & 3.1 & 10.69 \\
\hline $\mathrm{C} 1 \mathrm{~s}, \mathrm{O}-\mathrm{C}=\mathrm{O}$ & 288.51 & 2.835 & 14.789 & 288.8 & 2.148 & 2.416 \\
\hline $\mathrm{O} 1 \mathrm{~s}, \mathrm{Fe}-\mathrm{O}, \mathrm{In}-\mathrm{O}$ & 530.41 & 2.429 & 7.819 & 529.95 & 2.702 & 23.538 \\
\hline $\mathrm{O} 1 \mathrm{~s}, \mathrm{C}-\mathrm{O}-\mathrm{C}$ & 531.9 & 2.247 & 12.973 & 531.74 & 2.937 & 8.879 \\
\hline $\mathrm{O} 1 \mathrm{~s}, \mathrm{O}-\mathrm{C}=\mathrm{O}$ & 533.04 & 2.806 & 5.139 & 533.32 & 2.241 & 3.985 \\
\hline $\mathrm{O} 1 \mathrm{~s}, \mathrm{H}_{2} \mathrm{O}$ & 535.36 & 2.222 & 2.19 & - & - & - \\
\hline $\mathrm{Fe}^{2+} 2 \mathrm{p} 3 / 2$ & & & & 710.42 & 3.966 & 2.031 \\
\hline $\mathrm{Fe}^{3+} 2 \mathrm{p} 3 / 2$ & & & & 712.14 & 3.029 & 3.656 \\
\hline $\mathrm{Fe}^{2+} 2 \mathrm{p} 1 / 2$ & & & & 713.9 & 3.948 & 3.334 \\
\hline $\mathrm{Fe}^{3+} 2 \mathrm{p} 1 / 2$ & & & & 716.26 & 4.37 & 1.613 \\
\hline $\mathrm{Fe}^{2+} 2 \mathrm{p} 3 / 2$ satellite & & & & 720 & 3.736 & 0.8 \\
\hline $\mathrm{Fe}^{3+} 2 \mathrm{p} 3 / 2$ satellite & & & & 722.86 & 4.059 & 1.966 \\
\hline $\mathrm{Fe}^{2+} 2 \mathrm{p} 1 / 2$ satellite & & & & 725.42 & 3.378 & 3.54 \\
\hline $\mathrm{Fe}^{3+} 2 \mathrm{p} 1 / 2$ satellite & & & & 727.3 & 4.262 & 3.229 \\
\hline
\end{tabular}

The peak assigned to $\mathrm{O} 1 \mathrm{~s}$ of $\mathrm{H}_{2} \mathrm{O}$ at $535.4 \mathrm{eV}$ completely disappeared after adsorption due to the probable exclusion of water molecules from the protective polymer shell on MNPs, an indication of the close proximity of P(PEGMA-AA) with the MNP surface and, possibly, the effect of $\mathrm{CH}_{3}$ groups accumulation in the adsorption layer.

\subsection{Characterization of size, charge and aggregation state of naked and core- shell MNPs in biorelevant medium}

As the primary determining factors for colloidal stability in aqueous media are ionic strength and $\mathrm{pH}$, the biologically relevant medium for the nanoparticle dispersions was approximated by adding salt $(\mathrm{NaCl})$ to fix the ionic strength and adjusting the $\mathrm{pH}$ between 3 and 10.

Magnetite nanoparticles have a $\mathrm{pH}$-dependent surface charging feature in aqueous media with a point of zero charge (PZC) at $\mathrm{pH} \sim 8$ [8] (Fig. 4a blue circles, dashed line). Below this $\mathrm{pH}$ they become positively and above it negatively charged. Near the $\mathrm{pH}$ of PZC, large aggregates form even at low (10 mM) ionic strength (Fig. 4a, red circles, dashed line) as 
the particles are not stabilized electrostatically. However, binding anionic adsorbates to the MNP surface can provide excess negative charges, by which electrostatic stabilization can be achieved in a relatively wide range of $\mathrm{pHs}$ including $\mathrm{pH}$ of PZC. The blue and red squares and continuous lines in Fig. 4a show the shifts in the zeta potential and the hydrodynamic diameter, respectively, at $2.2 \mathrm{mmol}-\mathrm{COO} / \mathrm{g}$ MNP of P(P(GEMA-AA) loading.

Fig. $4 \mathrm{~b}$ demonstrates how the hydrodynamic diameter and zeta potential of originally naked MNPs change in response to P(PEGMA-AA) adsorption at $\mathrm{pH} \sim 6.5$ and $I=10 \mathrm{mM}$. At the given $\mathrm{pH}$ and ionic strength, the naked MNPs are aggregated, the measured $\mathrm{Z}$ average size is above $1000 \mathrm{~nm}$ at zero P(PEGMA-AA) loading. The size of the aggregates increases gradually up to about $0.1-0.2 \mathrm{mmol}-\mathrm{COO} / \mathrm{g} \mathrm{MNP}$ of polymer loading due to compensating the small amount of positive charges of the MNPs and reaching an isoelectric point (Fig. 4b blue curve crosses $\mathrm{x}$-axis). Before the isoelectric state is reached, the polyanions adsorb in a patch-wise manner on MNPs' surface, and so attraction between positively and negatively charged patches on neighbouring particles could lead to aggregation.

Sufficient pH-resistance is necessary for a multitude of biomedical applications. As it is seen in Fig. 4a, addition of P(PEGMA-AA) to MNPs at $2.2 \mathrm{mmol}-\mathrm{COO} / \mathrm{g}$ MNP concentration decreases the $\mathrm{pH}$ of the isoelectric point to $\mathrm{pH}$ below 3 and thus opens widely the pH-range of electrostatic stabilization. However, the electrokinetic potential could not be reduced more than to $\sim-35 \mathrm{mV}$ for the biologically relevant $\mathrm{pHs}$ around $\sim 6.5$. For electrostaticaly well stabilized particles, higher zeta potential values (e.g., at or even above $+/-50 \mathrm{mV}$ ) are more custom. In addition, the general aggregation range of hard colloidal particles lies somewhere within the $+/-25 \mathrm{mV}$ limits. Thus the $\sim-35 \mathrm{mV}$ result at $\mathrm{pH}=6.5$, taking in itself, would suggest a narrower pH-range of colloidal stability of P(PEGMAAA)@MNPs as compared, for example, with that of pure polyacrylate coatings on the MNPs (e.g., PAA [7] and PAM [8]). The high stability found in DLS experiments thus suggest the contribution of steric effect due to the well hydrated PEG-chains. The MNPs are likely stabilized by P(PEGMA-AA) according to the combined electrostatic and steric (i.e., electrosteric) mechanism.

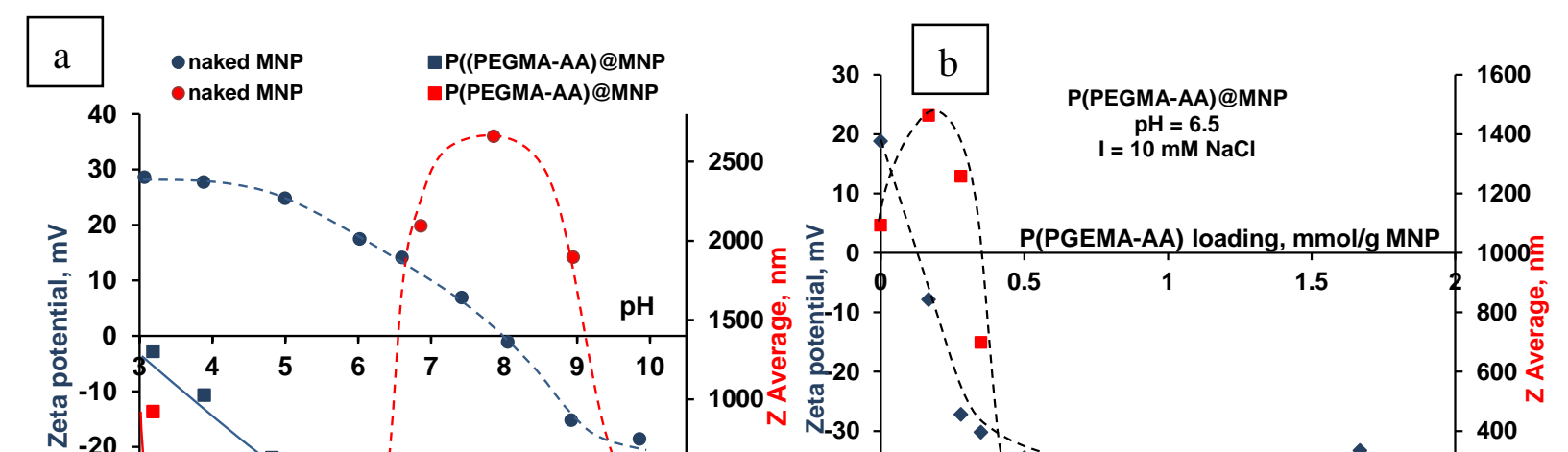


Fig. 4. (a) The pH dependence of the electrokinetic potential (Zeta potential) and the DLS mean hydrodynamic diameter ( $\left.\mathrm{Z}_{\text {Average }}\right)$ of naked and P(PEGMA-AA)-coated MNPs measured at polymer loading of $2.2 \mathrm{mmol}-\mathrm{COO} / \mathrm{g}$ MNP. (b) The changes in the Zeta potential and

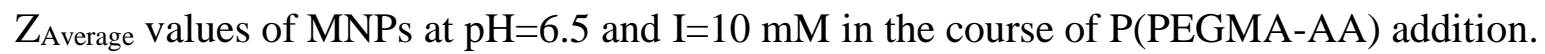

There is a substantial difference between the DLS (Fig. 4) and TEM (Fig. 2) mean sizes, the results being of 80-100 and $10 \mathrm{~nm}$ for the well stabilized (naked or coated) MNPs, respectively. This is due to the fact that in TEM images the clearly visible magnetite cores can be used for the analysis, while in DLS, the translational diffusion of particles is tested, which encounters the thickness of the coating and hydration shell of the particles as well.The lowend $\mathrm{pH}$ threshold of colloidal stability $(\mathrm{pH} 4)$ is smaller by 1 unit than it has been found previously for (PEG-acrylate-co-acrylic acid)-coated magnetite nanoparticles [9].

\subsection{Magnetic properties of the naked and core-shell MNPs}

For testing the theranostic potential of our novel product, we compared its response to static and alternating magnetic fields with that of original naked MNPs. The magnetization curves of both bare and P(PEGMA-AA)-coated MNPs measured by VSM (Fig. 5a) show no hysteresis. The absence of remanent magnetization is probably due to the rapid Néel relaxation, indicating that these particles are superparamagnetic at room temperature. This is in harmony with our expectations, because the primary size of the studied nanomagnets $(d$ TEM $\sim 10 \mathrm{~nm})$ is below the superparamagnetic limit of magnetite nanoparticles $(\sim 20 \mathrm{~nm})[23,39]$. The value of saturation magnetization is $\sim 58 \mathrm{emu} / \mathrm{g}$ for bare magnetite and $\sim 55 \mathrm{emu} / \mathrm{g}$ for coated particles (Table 2), both being lower than those of bulk magnetite, $92 \mathrm{emu} / \mathrm{g}$ likely due 
to nanoparticle surface effects [40-42]. The results harmonize with previously measured data $(\sim 55 \mathrm{emu} / \mathrm{g})$ for organic-coated nanoparticles $[4,43]$.

The frequency-dependent magnetic susceptibility spectra of bare and P(PEGMA-AA)coated MNPs are shown in Fig. 5b. Both Brownian and Néel relaxation mechanisms can be assumed if the particles as a whole and their inside magnetic moments are free to rotate in the frequency scan [44]. The real part of the susceptibility at the low frequency limit slightly decreased $(\sim 10 \%)$ and the characteristic frequency of Néel relaxation shifted from 1300 to $\sim 450 \mathrm{~Hz}$ as a result of coating the MNPs with the comb-like copolymer. The multi-core
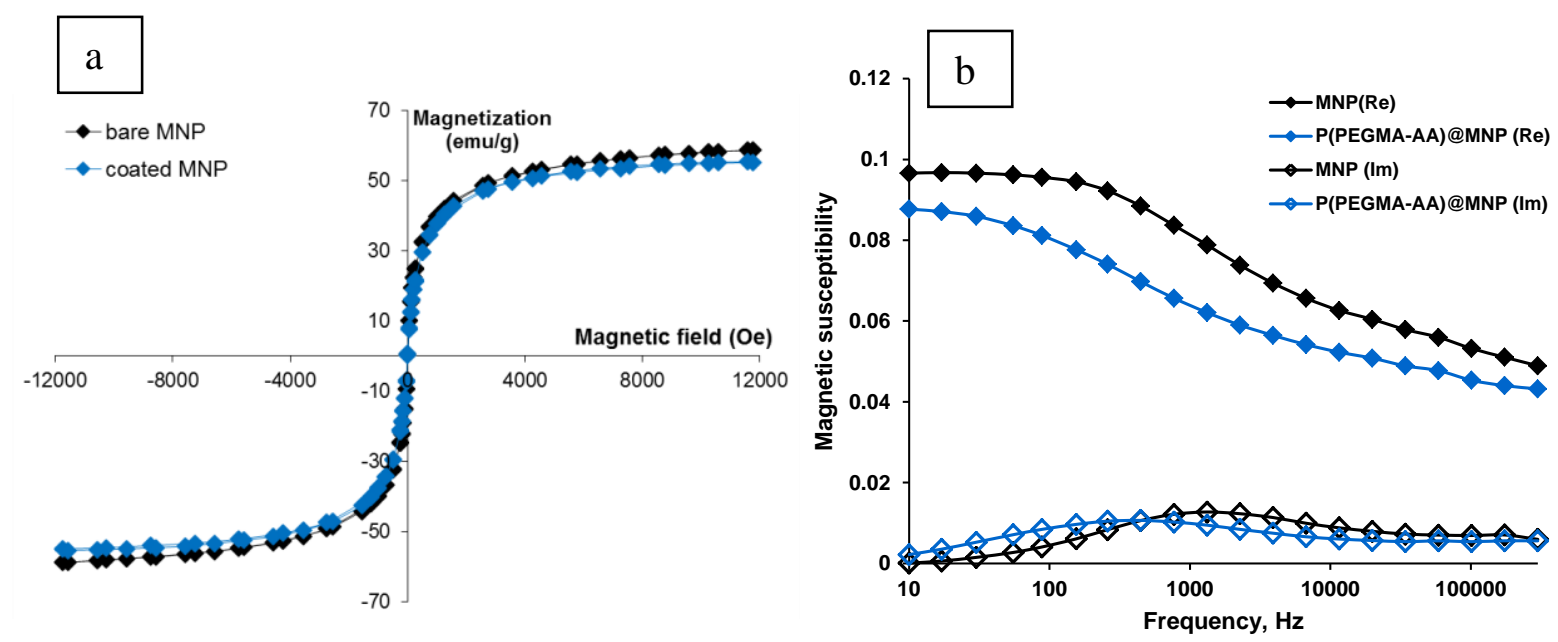

Fig. 5. Specific magnetization curve of bare and coated magnetite nanoparticles (a) and AC frequency-dependent volume susceptibility of bare and P(PEGMA-AA) coated MNPs (b).

(extended) model fit resulted in particle size distribution with hydrodynamic median diameters $d_{\mathrm{H}(\mathrm{AC})} \sim 70 \mathrm{~nm}$ with $\sigma=1.45$ for bare MNPs and $\sim 107 \mathrm{~nm}$ with $\sigma=1.65$ for P(PEGMA-AA)@MNPs (Table 2). The experiments indicate a mixture of Brownian and Néel relaxation responses. The large mean hydrodynamic diameter values can result from the contribution of the larger particles (no Brownian relaxation at higher frequencies), from clustered small particles $\left(d_{\text {TEM }} \sim 10 \mathrm{~nm}\right)$ with both Brownian and Néel relaxation or from clusters of multi-core particles (Brownian relaxation at higher frequencies). The obtained size averages $\left(d_{\mathrm{H}(\mathrm{AC})}\right)$ agree well with the DLS data ( Table 2 ) similarly to that in literature [45]. The frequency-dependent relaxation experiments reveal that the individuality of the MNPs has been preserved in the process of polyelectrolyte coating and that the formation of nanoparticle clusters of P(PEGMA-AA)@MNPs is similar to that of naked MNPs. 
Table 2. Magnetic properties and mean diameters of the bare and the coated nanoparticles

\begin{tabular}{|c|c|c|c|c|}
\hline \multirow{2}{*}{ Sample name } & \multicolumn{2}{|c|}{$\begin{array}{c}\text { Magnetic } \\
\text { experiments }\end{array}$} & \multicolumn{2}{|c|}{$\begin{array}{c}\text { Dynamic light } \\
\text { scattering }\end{array}$} \\
\hline & $\begin{array}{l}M \mathrm{~s} \\
(\mathrm{emu} / \mathrm{g})\end{array}$ & $\begin{array}{l}d_{\mathrm{H}(\mathrm{AC})} \\
(\mathbf{n m})\end{array}$ & $\begin{array}{l}d \mathrm{DLS} / \mathrm{Z}-\mathrm{Ave} \\
(\mathbf{n m})\end{array}$ & PDI \\
\hline $\mathrm{MNP}(\mathrm{pH} \sim 4)$ & 58.5 & 70 & 80 & 0.16 \\
\hline P(PEGMA-AA)@MNP (pH 6.5) & 55.2 & 107 & 103 & 0.15 \\
\hline
\end{tabular}

\subsection{Interaction of core-shell MNPs with cells - cell proliferation and internalization}

The antiproliferative assays were carried out in two types of cancer cell cultures MCF7 and T47D (Fig. 6). Both results show in fact negative growth inhibition revealing that the MNP fluid did not reduce cell proliferation. Similar negative cell growth inhibition was detected in the case of polygallate-coated MNPs, while humic acid, citric acid, polyacrylic acid and polyacrylic-co-maleic acid coated particles [46] somewhat reduced cell growth, albeit well below the limit of direct antiproliferative effect (25\% cell inhibition). We have used in previous antiproliferative assays four different cell lines [46] including both healthy and cancer cells for testing the biocompatibility of five different polyacid-coated MNPs. Our present and previous results taking together are in line with the observations of Thorat at al [47] who also found only slight variations in the viability of different cell lines after incubating them with polymer-encapsulated MNPs.

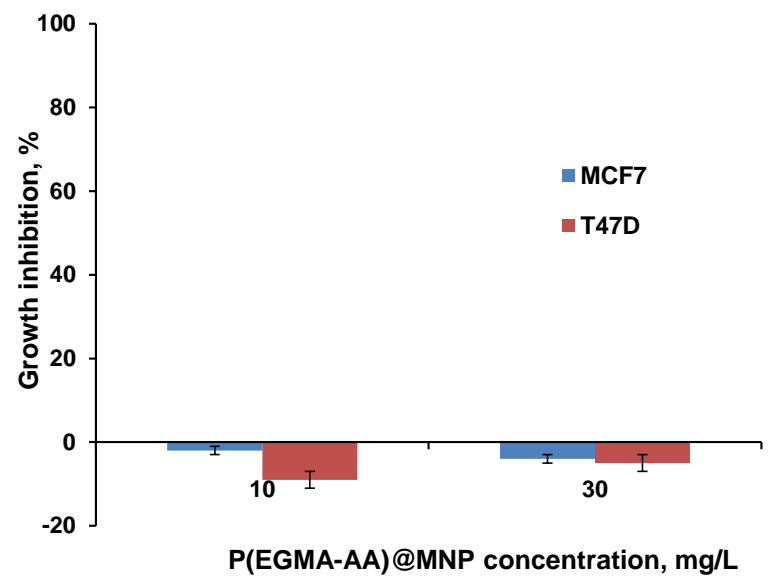


Fig. 6. MFC7 and T47D cancer cell growth inhibition results for the P(PEGMA-AA)@MNPs added to the cell cultures at 10 and $30 \mathrm{mg} / \mathrm{L}$ concentration. The error bars represent the average deviation of results (less than $\pm 2 \%$ ).

For theranostic applications, the interactions between the diagnostic-therapeutic nanoparticles and tissues or cells should be highly specific. The particles should carry biologically active functional groups for diagnosis and therapy, and should be resistant to nonspecific interactions with the biological medium [48], i.e., should only be recognised by specific cells. Although the P(PEGMA-AA) coating does not possess bioactive functionality, it comprises free carboxylic moieties (the AA-segments) to anchor such agents. When anionic carboxylates are exposed to the biological environment, some recognition reactions are expected to occur with the consequence of nanoparticle binding to cells and/or internalization via a non-specific route. Prussian blue staining of He-La cells cultured with P(PEGMAAA)@MNPs (Fig. 7), however, reveals that the nanoparticles could be fully removed from the cell population by washing because there is no blue spots on the photo (Fig. 7 top) at all, which proves the absence of non-specific interaction. The AA-segments thus appear to be hidden form the medium being probably buried under the hydrophilic PEG-layer and not exposed. A representative example of evident accumulation and internalization of MNPs is contrasted with it in Fig. 7: the incubation of He-La culture with citric acid coated MNPs (CA@MNPs) [4]. Previously tested other particles, PAA- and PAM-coated MNPs, showed as well some degree of internalization by He-La cells [4]. Due to the absence of non-specific binding of P(PEGMA-AA)@MNPs to the cells we can suppose that the particles are able to flow freely in the vascular system in the course of MRI diagnosis, or they can be freely guided to target for magnetic hyperthermia treatments. For the same reason, non-specific binding mechanisms would not likely compromise the action of a biological targeting function being attached to the particles. 
Fig. 7. Prussian blue staining of He-La cell culture. The cells were further cultured in the presence of MNPs at 10 (P(PEGMA-AA)@MNP) and 14.7 mg/L (CA@MNP [4]) concentrations, the latter used as a positive stain reference. The dark dots in the control and P(PEGMA)@MNP containing cell cultures are the residuals of not fully dissolved Prussian blue stain.

\subsection{Testing the hyperthermic efficiency of core-shell MNPs}

Calorimetric characterization of the P(PEGMA-AA)@MNPs was performed in magnetic hyperthermia experiments. We measured the heat evolution in parallel by using two different hyperthermia apparatuses to check the reliability of SAR (specific absorption rata) values. Our sample's SAR value obtained in the DM100 measurements was significantly higher than that measured in the magneTherm device at similar field settings (e.g., $50.3 \mathrm{~W} / \mathrm{g}$ at $323 \mathrm{kHz} / 15.9 \mathrm{kA} / \mathrm{m}$ in DM100 while $17.44 \mathrm{~W} / \mathrm{g}$ at $329 \mathrm{kHz} / 13.13 \mathrm{kA} / \mathrm{m}$ in magneTherm). Our DM100 results are in full harmony with SAR values obtained by Kolen'ko and coworkers [30] for polyacrylic acid coated magnetite nanoparticles measured under similar conditions (DM100 instrument, $300 \mathrm{kHz} / 12 \mathrm{kA} / \mathrm{m}$ ). However, the strong discrepancy between the SAR values obtained for same materials in different experiments is known in literature $[49,50]$. The main reason for that is probably the lack of a standardized protocol and, consequently, many aspects of the experimental conditions vary uncontrollably among the measuring locations. It is also known that the structure and chemical composition of magnetic nanoparticles and their coating and the viscosity of the suspending medium as well have a tremendous effect on the heat producing efficiency [47,50-52]. The latter 
parameters control the ratio of Brownian and Néel mechanisms in the process of magnetic relaxation and so by their optimization the SAR values can be maximized for a given nanoparticle dispersion. For example, Thorat and coworkers achieved SAR values at the level of $400 \mathrm{~W} / \mathrm{g}$, both for iron oxide [51] and $\mathrm{La}_{1-\mathrm{x}}-\mathrm{Sr}_{\mathrm{x}}-\mathrm{MnO}_{3}$ [47,52] nanoparticles at higher magnetic field strengths $(\sim 40 \mathrm{kA} / \mathrm{m})$ by designing specific polymer coatings. Currently, the RADIOMAG COST action (TD1402) is working on the problems of experimental protocol unification in order to obtain reproducible results for identical nanoparticle systems at different laboratories. We discuss the hyperthermia effect of P(PEGMA-AA)@MNPs based on our experiments performed in the magneTherm instrument. The heat production was tested at two frequencies with different field strengths: $\mathrm{H}_{0}=19.59,16.39,11.46,7.28$ and 4.91 $\mathrm{kA} / \mathrm{m}$ at $110.7 \mathrm{kHz}$ and $13.13,10.94$ and $5.47 \mathrm{kA} / \mathrm{m}$ at $329 \mathrm{kHz}$. The SAR values were

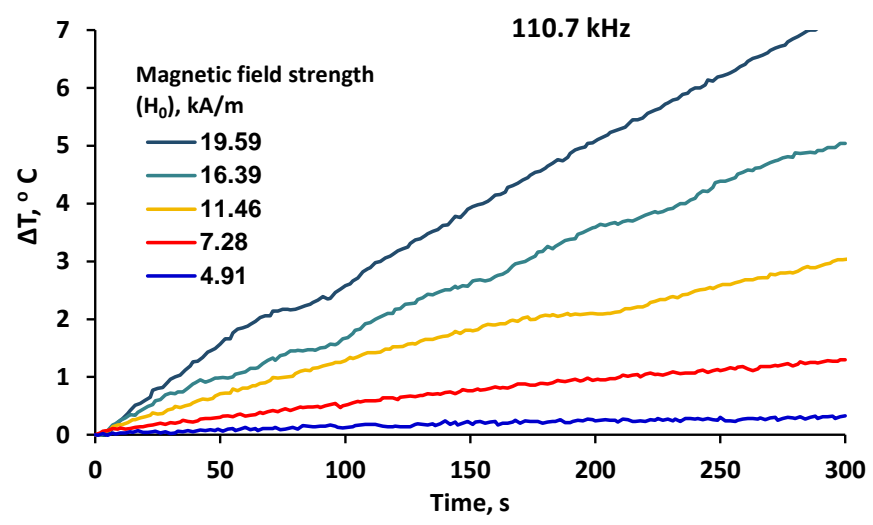

Fig. 8. Heating curves of the P(PEGMA-AA)@MNPs measured in magnetic hyperthermia experiments at $110.7 \mathrm{kHz}$ field frequency and five different field strength values.

between 14.22 and $2.17 \mathrm{~W} / \mathrm{g}$ at $110.7 \mathrm{kHz}$ and between 17.44 and $8.72 \mathrm{~W} / \mathrm{g}$ at $329 \mathrm{kHz}$. The magnetic field independent ILP (intrinsic loss power) values varied around 0.3 as calculated from the initial rate of heat evolution, $(\Delta T / \Delta t)_{t=0}$. The product of the field values $\left(f \cdot H_{0}\right)$ in our experiments is close to the estimated upper limit of safe human application of alternate magnetic fields known as the Brezovich criterion [39,49,53]. Fig. 8 shows the primary heating curves for the magnetic field frequency of $110.7 \mathrm{kHz}$ and Fig. 9 demonstrates the fielddependence of the heating rate of the P(PEGMA-AA)@MNP dispersion. Plots of experimental results for 110.7 and $329 \mathrm{kHz}$ are seen in Fig. 9a and b, respectively. The fits of $(\Delta \mathrm{T} / \Delta \mathrm{t})_{\mathrm{t}=0}=(\mathrm{H} / a)^{n}$ were used to calculate the relative contribution of Néel relaxation and Brownian hysteresis heating to the gross experimental heat evolution based on the theory of Skumiel [54]. The exponent $n$ was found to be 2.0633 for the $110.7 \mathrm{kHz}$ and 2.002 for the 329 $\mathrm{kHz}$ experiments, and the values of $a$ were 110 and 76, respectively. The linear plots of the 

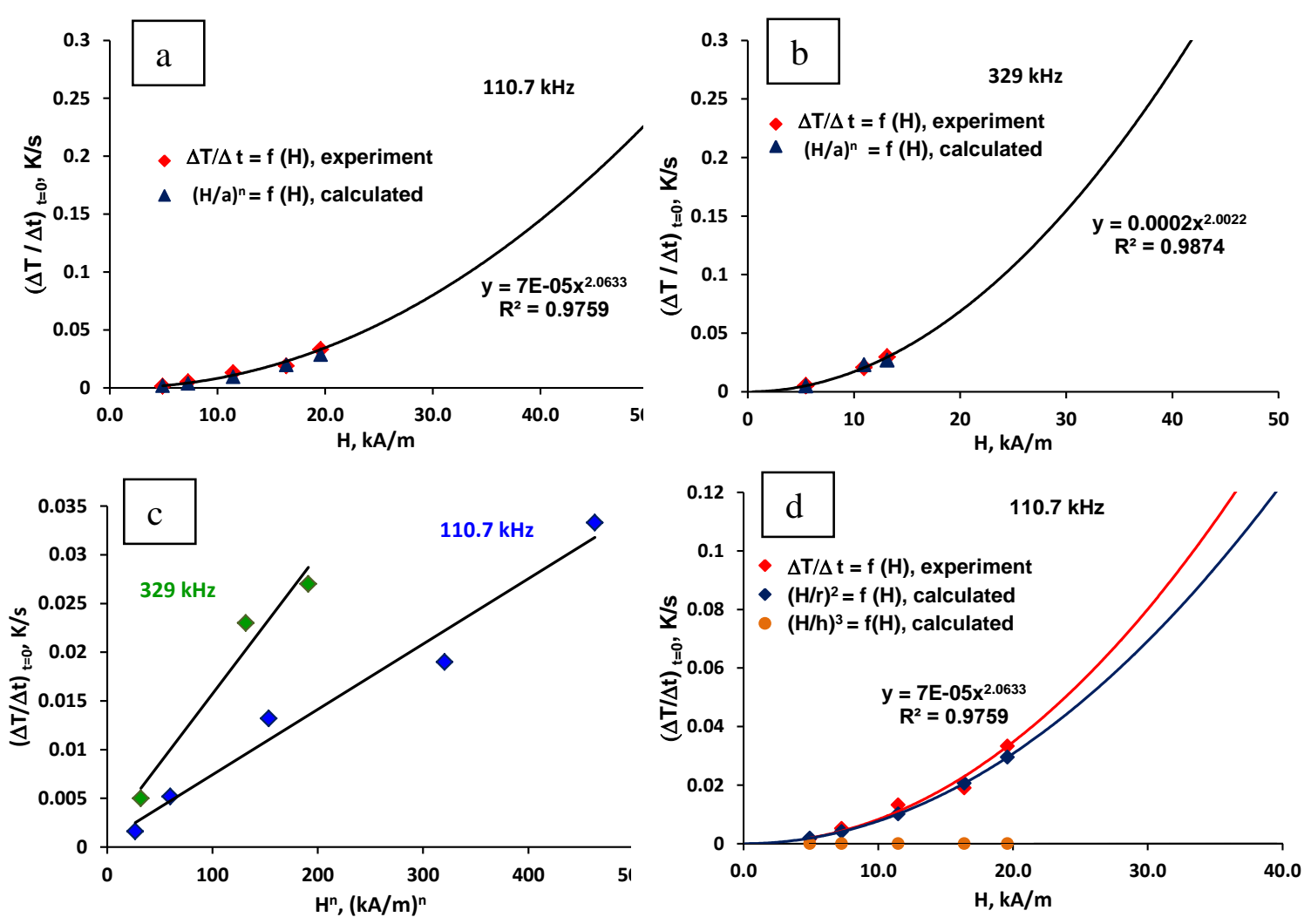

Fig. 9. Results of magnetic hyperthermia experiments of P(PEGMA-AA) @ MNPs carried out at frequencies of 110.7 and $329 \mathrm{kHz}$. See the explanations of panels a, b, c and d in the text. The SAR values are between 14.22 and $2.17 \mathrm{~W} / \mathrm{g}$ at $110.7 \mathrm{kHz}$ and between 17.44 and 8.72 $\mathrm{W} / \mathrm{g}$ at $329 \mathrm{kHz}$.

initial heat evolution as a function of $\mathrm{H}^{n}$ are seen in Fig. 9c. $(\mathrm{H} / a)^{n}$ is a linear combination of the Néel and Brownian components as $(\mathrm{H} / a)^{n}=(\mathrm{H} / r)^{2}+(\mathrm{H} / h)^{3}$ [54], where $r$ and $h$ are the fitting parameters referring to the losses from relaxational mechanism and hysteresis, respectively. Our experiments show that the heat produced by P(PEGMA-AA)@MNPs under alternate magnetic field is practically due to the Néel relaxation mechanism solely, because the exponents $n$ of the experimental field strength-function were very close to 2 at both frequencies. The plots of the $(\mathrm{H} / \mathrm{r})^{2}$ and $(\mathrm{H} / \mathrm{h})^{3}$ components measured at $110.7 \mathrm{kHz}$ are presented in Fig. 9d. For larger particles or aggregated units of small particles, the main heating mechanism is through hysteresis loss. In AC susceptibility experiments (Fig. 5), we have observed the characteristics of a hysteresis loss as well for P(PEGMA-AA)@MNPs, which revealed the presence of larger nanoparticle clusters $(\sim 100 \mathrm{~nm}$ in diameter $)$ in the 
sample besides individual particles. However, the magnetic susceptibility of the cluster structures became observable only at very low frequencies $(<\sim 10 \mathrm{kHz})$ and it did not contribute to the heating behaviour at higher frequencies. This result reveals that the superparamagnetic magnetite nanoparticles of $\sim 10 \mathrm{~nm}$ diameter are well suited for magnetic hyperthermia in biological tissues or cells even if they are eventually arranged in larger clusters. In the presence of larger clusters, in which the state of MNPs is similar to that localized in biological media [54], the magnetic hyperthermia effect is still fully due to the relaxational loss of single magnetic domains of the primary particles.

\section{Conclusions}

Here we report on a new generation of coating materials P(PEGMA-AA), which integrate anionic groups (i.e., carboxyl groups capable anchoring both nanoparticles and bioactive molecules) and highly hydrophilic uncharged segments (i.e., PEG chains in comblike arrangement). This copolymer can spontaneously adsorb on iron oxide surface via multipoint bindings to $\equiv \mathrm{Fe}-\mathrm{OH}$ surface sites and so the preparation of core-shell magnetite nanoparticles, P(PEGMA-AA)@MNPs, was simple.

Colloidal stability experiments revealed that the particles are stabilized according to the electrosteric (i.e., combined electrostatic and steric) mechanism, in accord with the structure of the polymer coating molecule.

Interestingly, despite the highly charged nature of the core-shell MNPs at biologically relevant $\mathrm{pH}$ and ionic strength, the particles have not been internalized by He-La cells, which is in contrast to the behavior of other MNPs coated with conventional polyacrylates. We could conclude that this difference is likely due to the presence of PEG quills that bury the charged carboxylate groups inside the coating layer thus preventing them from non-specific interaction with proteins in the cell culture. The coating of P(PEGMA-AA)@MNPs provides a nonfouling outer surface that helps the nanoparticles to remain "invisible" for the phagocytic mechanisms. In parallel with this, the P(PEGMA-AA)@MNPs improved somewhat the proliferation of the cells of two tested cell lines as compared with their cultivation in a general minimal essential medium.

An advantageous feature of the core-shell MNPs is that free carboxylate moieties are in the coating shell that can be exploited for attaching specific biologically active molecules or proteins for theranostic applications. The theranostic capability of the naked and coated 
MNPs was compared in magnetic experiments (static magnetization and frequency-dependent magnetic susceptibility measurements) and we found that the coating did not alter significantly the original magnetic properties of MNPs. The analysis of the frequencydependent susceptibility curves implies the multicore feature of magnetic nanoparticles. Magnetic hyperthermia measurements conducted at different frequency and field strength values revealed several degrees of heat production (up to 5 degrees) with SAR values between 17.44 and $2.17 \mathrm{~W} / \mathrm{g}$. The formation of magnetic multicores may be beneficial for heat production.

\section{Acknowledgement}

Authors are grateful to Andrea Majzik (Supramolecular and Nanostructured Materials Research Group of the Hungarian Academy of Sciences, University of Szeged) for the TEM pictures and to Christian Jonasson, Fredrik Ahrentorp and Christer Johansson (Acreo, Sweden) for AC susceptibility measurements. The research was supported by OTKA [NK 84014] grant and the 'National Excellence Program' in the framework of TÁMOP-4.2.4.A/211/1-2012-000, co-financed by the European Union and the State of Hungary. This article is based upon work from COST Action RADIOMAG [TD1402], supported by COST (European Cooperation in Science and Technology).

\section{References}

1 A. S. Wadajka, J. U. Menon. T. Kadapure, R. T. Tran, J. Yang, K. T. Nguyen, Design and Application of Magnetic-based Theranostic Nanoparticle Systems, Recent Pat. Biomed. Eng. 6 (2013) 47-57.

2 E. Amstad, M. Textor, E. Reimhult, Stabilization and functionalization of iron oxide nanoparticles for biomedical applications, Nanoscale 3 (2011) 2819-43.

3 C. Blanco-Andujar, D. Ortega, P. Southern, Q. A. Pankhurst, N. T. K. Thanh, High performance multi-core iron oxide nanoparticles for magnetic hyperthermia: microwave synthesis, and the role of core-to-core interactions, Nanoscale 7 (2015) 1768-1775.

4 M. Szekeres, I. Y. Tóth, E. Illés, A. Hajdú, I. Zupkó, K. Farkas, G. Oszlánczi, L. Tiszlavicz, E. Tombácz, Chemical and colloidal stability of carboxylated core-shell 
magnetite nanoparticles designed for biomedical applications, Int. J. Mol. Sci. 14 (2013) 14550-14574.

5 C. Boyer, M. R. Whittaker, V. Bulmus, J. Liu, T. P. Davis, The design and utility of polymer-stabilized iron-oxide nanoparticles for nanomedicine applications, NPG Asia Mater. 2 (2010) 23-30.

6 R. A. Revia, M. Zhang, Magnetite nanoparticles for cancer diagnosis, treatment, and treatment monitoring: recent advances, Mater. Today 19 (2015) 157-168.

7 A. Hajdú, M. Szekeres, I. Y. Tóth, R. A. Bauer, J. Mihály, I. Zupkó, E. Tombácz, Enhanced stability of polyacrylate-coated magnetite nanoparticles in biorelevant media, Colloids Surf. B 94 (2012) 242-249.

8 I. Y. Tóth, E. Illés, R. A. Bauer, D. Nesztor, M. Szekeres, I. Zupkó, E. Tombácz, Designed polyelectrolyte shell on magnetite nanocore for dilution-resistant biocompatible magnetic fluids, Langmuir 28 (2012) 16638-46.

9 E. Illés, E. Tombácz, M. Szekeres, I. Y. Tóth, Á. Szabó, B. Iván, Novel carboxylated PEG-coating on magnetite nanoparticles designed for biomedical applications, J. Magn. Magn. Mater. 380 (2015) 132-139.

10 S. P. Schwaminger, S. A. Blank-Shim, I. Scheifele, P. Fraga-García, S. Berensmeier, Peptide binding to metal oxide nanoparticles, Faraday Discuss. (2017) Advance Article DOI: $10.1039 / C 7 F D 00105 C$

11 K. C. Barick, S. Singh, D. Bahadur, M. A. Lawande, D. P. Patkar, P. A. Hassan, Carboxyl decorated $\mathrm{Fe}_{3} \mathrm{O}_{4}$ nanoparticles for MRI diagnosis and localized hyperthermia, J. Colloid Interface Sci. 418 (2014) 120-125.

12 S. Winzen, S. Schoettler, G. Baier, C. Rosenauer, V. Mailaender; K. Landfester, K. Mohr, Complementary analysis of the hard and soft protein corona: sample preparation critically effects corona composition, Nanoscale 7 (2015) 2992-3001.

13 A. Jedlovszky-Hajdú, F. B. Bombelli, M. P. Monopoli, E. Tombácz, K. A. Dawson, Surface coatings shape the protein corona of SPIONs with relevance to their application in vivo, Langmuir 28 (2012) 14983-14991.

14 L. E. van Vlerken, T. K. Vyas, M. M. Amiji, Poly (ethylene glycol)-modified nanocarriers for tumor-targeted and intracellular delivery, Pharm. Res. 24 (2007) 14051414.

15 Q. A. Pankhurst, N. T. K. Thanh, S. K. Jones, J. Dobson, Progress in applications of magnetic nanoparticles in biomedicine, J. Phys. D. Appl. Phys. 42 (2009) 224001.

16 O. Veiseh, J. W. Gunn, M. Zhang, Design and fabrication of magnetic nanoparticles for 
targeted drug delivery and imaging, Adv. Drug Deliv. Rev. 62 (2010) 284-304.

17 P. E. Scopelliti, Borgonovo, M. Indrieri, L. Giorgetti, G. Bongiorno, R. Carbone, A. Podestà, P. Milani, The effect of surface nanometre-scale morphology on protein adsorption, PLoS One 5 (2010) e11862.

18 J.-F. Lutz, Polymerization of oligo(ethylene glycol) (meth)acrylates: Toward new generations of smart biocompatible materials, J. Polym. Sci. A Polym. Chem. 46 (2008) 3459-3470.

19 A. Bakandritsos, A. Papagiannopoulos, E. N. Anagnostou, K. Avgoustakis, R. Zboril, S. Pispas, J. Tucek, V. Ryukhtin, N. Bouropoulos, A. Kolokithas-Ntoukas, T. A. Steriotis, U. Keiderling, F. Winnefeld, Merging high doxorubicin loading with pronounced magnetic response and bio-repellent properties in hybrid drug nanocarriers, Small 8 (2012) 2381-2393.

20 T. T. T. N'Guyen, H. T. T. Duong, J. Basuki, V. Montembault, S. Pascual, C. Guibert, J. Fresnais, C. Boyer, M. R. Whittaker, T. P. Davis, L. Fontaine, Functional iron oxide magnetic nanoparticles with hyperthermia-induced drug release ability by using a combination of orthogonal click reactions, Angew. Chemie - Int. Ed. 52 (2013) 1415214156.

21 M. Lattuada, T. A. Hatton, Functionalization of monodisperse magnetic nanoparticles, Langmuir 23 (2007) 2158-68.

22 E. Tombácz, E. Illés, A. Majzik, A. Hajdú, N. Rideg, M. Szekeres, Ageing in the inorganic nanoworld: example of magnetite nanoparticles in aqueous medium, Croat. Chem. Acta 80 (2007) 503-515.

23 R. M. Cornell, U. Schwertmann, The Iron Oxides, first ed., Wiley-VCH, Weinheim, 1996.

24 A. K. Gupta, A. S. G. Curtis, Lactoferrin and ceruloplasmin derivatized superparamagnetic iron oxide nanoparticles for targeting cell surface receptors, Biomaterials 25 (2004) 3029-3040.

25 T. J. Mosmann, Rapid colorimetric assay for cellular growth and survival: application to proliferation and cytotoxicity assays, J. Immunol. Methods 65 (1983) 55-63.

26 E. Tombácz, R. Turcu, V. Socoliuc, L. Vékás, Magnetic iron oxide nanoparticles: Recent trends in design and synthesis of magnetoresponsive nanosystems, Biochem. Biophys. Res. Commun. 468 (2015) 442-453.

27 H.-C. Roth, S. P. Schwaminger, M. Schindler, F. E. Wagner, S. Berensmeier, 
Influencing factors in the co-precipitation process of superparamagnetic iron oxide nano particles: a model based study, J. Magn. Magn. Mater. 377 (2015) 81-89.

28 R. Ahmadi, N. Gu, H. Reza, M. Hosseini, Characterization of cysteine coated magnetite nanoparticles as MRI contrast agent, Nano-Micro Lett. 4 (2012) 180-183.

29 S. R. Kumar, L. Marianna, S. Gianni, J. Nathanael, S. I. Hong, T. Hwan Oh, D. Mangalaraj, C. Viswanathan and N. Ponpandian, Hydrophilic polymer coated monodispersed $\mathrm{Fe}_{3} \mathrm{O}_{4}$ nanostructures and their cytotoxicity, Mater. Res. Express 1 (2014) 015015.

30 Y. V. Kolen'ko, M. Bañobre-López, C. Rodríguez-Abreu, E. Carbó-Argibay, A. Sailsman, Y. Piñeiro-Redondo, M. F. Cerqueira, D. Y. Petrovykh, K. Kovnir, O. I. Lebedev, J. Rivas, Large-scale synthesis of colloidal $\mathrm{Fe}_{3} \mathrm{O}_{4}$ nanoparticles exhibiting high heating efficiency in magnetic hyperthermia, J. Phys. Chem. C 118 (2014) 8691-8701.

31 B. Michen, C. Geers, D. Vanhecke, C. Endes, B.Rothen-Rutishauser, S. Balog, A. Petri-Fink, Avoiding drying-artifacts in transmission electron microscopy: characterizing the size and colloidal state of nanoparticles, Sci Rep. 5 (2015) 9793.

32 D. Susan-Resiga, V.Socoliuc, T.Boros, T. Borbáth, O. Marinica, A. Han, L.Vékás, The influence of particle clustering on the rheological properties of highly concentrated magnetic nanofluids, J. Colloid Interface Sci. 373 (2012) 110-115.

33 A. M. Atta, G. A. El-Mahdy, H. A. Al-Lohedan, S. A. Al-Hussain, Synthesis of environmentally friendly highly dispersed magnetite nanoparticles based on rosin cationic surfactants as thin film coatings of steel, Int. J. Mol. Sci. 15 (2014) 69746989.

34 M. Descostes, F. Mercier, N. Thromat, C. Beaucaire, M. Gautier-Soyer, Use of XPS in the determination of chemical environment and oxidation state of iron and sulfur samples: constitution of a data basis in binding energies for $\mathrm{Fe}$ and $\mathrm{S}$ reference compounds and applications to the evidence of surface species of an oxidized pyrite in a carbonate medium, Appl. Surf. Sci. 165 (2000) 288-302.

35 G. Bhargava, I. Gouzman, C. M. M. Chun, T. A. Ramanarayanan, S. L. Bernasek, Characterization of the "native" surface thin film on pure polycrystalline iron: A high resolution XPS and TEM study, Appl. Surf. Sci. 253 (2007) 4322-4329.

36 I. Y. Tóth, M. Szekeres, R. Turcu, S. Sáringer, E. Illés, D. Nesztor, E. Tombácz, Mechanism of in situ surface polymerization of gallic acid in an environmentalinspired preparation of carboxylated core-shell magnetite nanoparticles, Langmuir 30 
(2014) 15451-15461.

37 I. Y. Tóth, E. Illés, M. Szekeres, E. Tombácz, Preparation and characterization of chondroitin-sulfate-A-coated magnetite nanoparticles for biomedical applications, J. Magn. Magn. Mater. 380 (2015) 168-174.

38 XPS, AES, UPS and ESCA - LaSurface.com, http://www.lasurface.com/accueil/index.php (Accessed 28 Nov 2017)

39 D. Ortega, Q. A. Pankhurst, Magnetic hyperthermia, in: P. O'Brien (ed), Nanoscience, Volume 1, Nanostructures through Chemistry, Royal Society of Chemistry, Cambridge, 2013, pp. 60-88.

40 K. L. Krycka, R. A. Booth, C. R. Hogg, Y. Ijiri, J. A. Borchers, W. C. Chen, S. M. Watson, M. Laver, T. R. Gentile, L. R. Dedon, S. Harris, J. J. Rhyne, S. A. Majetich, Core-shell magnetic morphology of structurally uniform magnetite nanoparticles, Phys. Rev. Lett. 104 (2010) 207203.

41 B. Luigjes, S. M. C. Woudenberg, R. De Groot, J. D. Meeldijk, H. M. Torres Galvis, K. P. De Jong, A. P. Philipse, B. H. Erné, Diverging geometric and magnetic size distributions of iron oxide nanocrystals, J. Phys. Chem. C 115 (2011) 14598-14605.

42 C. Pereira, A. M. Pereira, C. Fernandes, M. Rocha, R. Mendes, M. P. FernándezGarcía, A. Guedes, P. B. Tavares, J.-M. Grenèche, J. P. Araújo, C. Freire, Superparamagnetic $\mathrm{MFe}_{2} \mathrm{O}_{4}(\mathrm{M}=\mathrm{Fe}, \mathrm{Co}, \mathrm{Mn})$ nanoparticles: Tuning the particle size and magnetic properties through a novel one-step coprecipitation route, Chem. Mater. 24 (2012) 1496-1504.

43 S. van Berkum, J. Dee, A. Philipse, B. Erné, Frequency-Dependent Magnetic Susceptibility of Magnetite and Cobalt Ferrite Nanoparticles Embedded in PAA Hydrogel, Int. J. Mol. Sci. 14 (2013) 10162-10177.

44 F. Ahrentorp, A. Astalan, J. Blomgren, C. Jonasson, E. Wetterskog, P. Svedlindh, A. Lak, F. Ludwig, L. J. van Ijzendoorn, F. Westphal, C. Grüttner, N. Gehrke, S. Gustafsson, E. Olsson, C. Johansson, Effective particle magnetic moment of multicore particles, J. Magn. Magn. Mater. 380 (2015) 221-226.

45 S. Bogren, A. Fornara, F. Ludwig, M. Puerto Morales, U. Steinhoff, M. Fougt Hansen, O. Kazakova, C. Johansson, Classification of Magnetic Nanoparticle Systems Synthesis, Standardization and Analysis Methods in the NanoMag Project, Int. J. Mol. Sci. 16 (2015) 20308-20325. 
46 E. Tombácz, M. Szekeres, A. Hajdú, I. Y. Tóth, R. A. Bauer, D. Nesztor, E. Illés, I. Zupkó, L. Vékás, Colloidal stability of carboxylated iron oxide nanomagnets for biomedical use, Period. Polytech. Chem. Eng. 58(Sup) (2014) 3-10.

47 N. D. Thorat, R. A. Bohara, V. Malgras, S. A. M. Tofail, T. Ahamad, S. M. Alshehri, K. C.-W. Wu, Y. Yamauchi, Multimodal superparamagnetic nanoparticles with unusually enhanced specific absorption rate for synergetic cancer therapeutics and magnetic resonance imaging, Appl. Mater. Interfaces 8 (2016) 14656-14664.

48 P. Decuzzi, M. Ferrari, The role of specific and non-specific interactions in receptormediated endocytosis of nanoparticles, Biomaterials 28 (2007) 2915-2922.

49 E. A. Perigo, G. Hemery, O. Sandre, D. Ortega, E. Garaio, F. Plazaola, F. J. Teran, Fundamentals and advances in magnetic hyperthermia, Appl. Phys. Rev. 2 (2015) 041302 .

50 M. L. Etheridge, N. Manucherabadi, R. R. Franklin, J. C. Bischof, Superparamagnetic iron oxide nanoparticles heating: Basic tutorial, in W. J. Minkowycz, E. M. Sparrow, J. P. Abraham (eds), Nanoparticle Heat Transfer and Fluid Flow, CRC Press Boca Raton, 2017, pp. 97-122.

51 N. D. Thorat, O. M. Lemine, Raghvendra A. Bohara, K. Omri, L. El Mircd, S. A. M. Tofail, Superparamagnetic iron oxide nanocargoes for combined cancer thermotherapy and MRI applications, Phys. Chem. Chem. Phys. 18 (2016) 2133121339.

52 N. D. Thorat, R. A. Bohara, M. R. Noor|, D. Dhamecha, T. Soulimane|, S. A. M. Tofail, Effective cancer theranostics with polymer encapsulated superparamagnetic nanoparticles: Combined effects of magnetic hyperthermia and controlled drug release, Biomater. Sci. Eng. 3 (2017) 1332-1340.

53 I. A. Brezovich, Low frequency hyperthermia: Capacitive and ferromagnetic thermoseed methods, Med. Phys. Monogr. 16 (1988) 82-111.

54 A. Skumiel, Evaluation of relaxational and hysteretic heat losses in concentrated magnetic fluid under influence of alternating magnetic field, Int. J. Thermophys. 31 (2010) 546-555. 